\title{
Hormonal Regulation of Hematopoietic Stem Cells and Their Niche: A Focus on Estrogen
}

\author{
Hye-Ryeon $\mathrm{Heo}^{1}$, Li Chen ${ }^{3}$, Borim $\mathrm{An}^{1}$, Kye-Seong Kim${ }^{4}$, Junfeng $\mathrm{Ji}^{3}$, Seok-Ho Hong ${ }^{1,2}$ \\ ${ }^{1}$ Department of Internal Medicine, School of Medicine, Kangwon National University, Chuncheon, Korea, \\ ${ }^{2}$ Stem Cell Institute, Kangwon National University, Chuncheon, Korea, ${ }^{3}$ Center of Stem Cell and Regenerative Medicine, \\ School of Medicine, Zhejiang University, Hangzhou, Zhejiang Province, China, ${ }^{4}$ Graduate School of Biomedical Science and \\ Engineering, Department of Biomedical Science, Hanyang University, Seoul, Korea
}

Self-renewal and differentiation are hallmarks of stem cells and controlled by various intrinsic and extrinsic factors. Increasing evidence indicates that estrogen (E2), the primary female sex hormone, is involved in regulating the proliferation and lineage commitment of adult and pluripotent stem cells as well as modulating the stem cell niche. Thus, a detailed understanding of the role of E2 in behavior of stem cells may help to improve their therapeutic potential. Recently, it has been reported that E2 promotes cell cycle activity of hematopoietic stem and progenitor cells and induces them to megakaryocyte-erythroid progenitors during pregnancy. This study paves the way towards a previously unexplored endocrine mechanism that controls stem cell behavior. In this review, we will focus on the scientific findings regarding the regulatory effects of E2 on the hematopoietic system including its microenvironment.

Keywords: Estrogen, Hematopoiesis, Niche, Stem cells

\section{Introduction}

Regenerative medicine is one of the most exciting frontiers in medicine which harnesses the self-renewal and differentiation capacity of stem cells for tissue regeneration $(1,2)$. Major progress has been made on defining the role of specific intrinsic or extrinsic factors in controlling proliferation and differentiation of stem cells for the past two decades (3). It is an essential part of regenerative medicine to develop clinically safer culture conditions as well as di-

Accepted for publication April 13, 2015, Published online May 30, 2015 Correspondence to Seok-Ho Hong

Department of Internal Medicine, School of Medicine, Kangwon National University, 192-1, Hyoja-dong, Chuncheon 200-701, Korea

Tel: +82-33-250-7819, Fax: +82-33-244-2367

E-mail: shhong@kangwon.ac.kr

(a) This is an open-access article distributed under the terms of the Creative Commons Attribution Non-Commercial License (http://creativecommons.org/ licenses/by-nc/4.0/), which permits unrestricted non-commercial use, distribution, and reproduction in any medium, provided the original work is properly cited. rect the differentiation of stem cells into functionally relevant specialized cells for therapy (4-6). However, there was relatively little consideration of the endocrine system including sex hormones and gender-specific regulation in stem cell research.

Hematopoietic stem cells (HSCs) constitute a rare subpopulation in the hematopoietic system that produces all the mature blood cells throughout life (3). Thus, the dynamic balance between quiescence, self-renewal and differentiation is a unique feature of HSCs, which is governed by multidimensional regulatory mechanisms including genetic and epigenetic regulation as well as specialized microenvironment, denoted as "niche" (7). A wealth of experimentation demonstrated that deregulation of intrinsic and extrinsic factors plays a key pathogenic role in a variety of hematopoietic diseases including leukemia (3). In recent years, a growing body of evidence suggests that estrogen (E2) is involved in regulating the proliferation and lineage commitment of multipotent and pluripotent stem cells as well as modulating the stem cell niche (8). It has long been known that E2 affects stem cells in tissues in- 
cluding sexual organs and brain that display sexual dimorphism (9). Notably, Nakada et al. (10) demonstrated that E2 regulates cell cycle activity of HSCs in the bone marrow (BM), which is a tissue that does not show sex-specific morphological differences. These findings shed new light on the specific interactions between endocrine and hematopoietic system. In this review, we focus on the biological actions of E2 related to the hematopoietic system including its niche.

\section{Modes of Estrogen Action: Genomic and Non-genomic pathways}

E2 is the primary female sex hormone and plays a key role in various physiological events such as pregnancy, menstrual cycle, vasculogenesis, bone formation and lipid metabolism (11-14). E2 exerts its biological effects through the genomic (nuclear) and non-genomic (extranuclear) signaling pathways $(15,16)$. The genomic action of E2 is mediated by estrogen receptor $\alpha$ and $\beta$ (ER- $\alpha$ and ER$\beta$ ), which are dimeric nuclear receptors that bind to specific sequences of DNA known as E2 response elements. The DNA-ER complex then interacts with other co-factors and modulates activation or repression of target genes. E2 also can regulate gene expression independent of classical genomic pathway. The non-genomic actions of E2 are mediated by intracellular second messengers such as cavelolin-1, striatin, receptor tyrosine kinases and $G$ protein-coupled receptor 30 (16). The non-genomic pathway confers the ability of the cell to rapidly respond to E2 stimulation. ER- $\alpha$ and/or ER- $\beta$ are detected in different types of stem cells including HSCs, which suggests that E2 signaling in stem cells may be primarily mediated by ER-dependent genomic pathway (8). In this review, we first summarize the current knowledge of the effects of E2 on the proliferation of multipotent and pluripotent stem cells.

\section{Effects of Estrogen on the Proliferation of BM-derived Mesenchymal Stem Cells}

Accumulating evidence shows that E2 is involved in regulating the proliferation of multipotent mesenchymal stem cells (MSCs). This proliferative effect of E2 has been well defined in BM-MSCs. Hong et al. (17) demonstrated that E2 significantly enhances the proliferation of human BM-MSCs obtained from healthy male and female donors. Interestingly, this study showed that a wider range of E2 concentrations was observed to significantly promote proliferation in male BM-MSCs $\left(1 \times 10^{-12}\right.$ to $\left.10^{-8} \mathrm{M}\right)$ compared with that in female BM-MSCs $\left(1 \times 10^{-8}\right.$ to $\left.10^{-10} \mathrm{M}\right)$. However, the molecular mechanisms of the gender differ- ence of E2 regulation are still not elucidated. Other studies demonstrated that E2 enhances the proliferation and osteogenic differentiation of BM-MSC cultures obtained from healthy women with postmenopausal osteoporosis by activating Notch signaling pathway and upregulation of ERs transcripts $(18,19)$. These findings suggest that modulation of BM-MSCs by E2 can be a novel therapeutic strategy for treating oesteporosis. In addition, resveratrol, a polyphenolic phytoestrogen, induces an increase of $\left[{ }^{3} \mathrm{H}\right]$-thymidine incorporation by human BM-MSCs derived from healthy donors, which is mediated via ER-dependent extracellular signal-regulated kinase 1/2 (ERK1/2) activation (20). The study indicates that synthetic or natural E2-like compounds including phytoestrogen may cause beneficial or adverse effects in stem cell behavior, which requires further investigations. Other studies indicate that the proliferative activity of E2 in MSCs is conserved across multiple tissues and species. Yun et al. (21) showed that E2 significantly increases $\left[{ }^{3} \mathrm{H}\right]$-thymidine incorporation and the percentage of human umbilical cord-derived MSC population in the $\mathrm{S}$ phase via HIF-1 $\alpha$ and VEGF expression through ER, protein kinase $\mathrm{C}, \mathrm{PI} 3 \mathrm{~K} / \mathrm{Akt}$, and mitogen-activated kinase pathways. Recent studies found that E2 increases the number of cells in CFU-F colonies derived from rat BM-MSCs and upregulates the expression of anti-apoptotic Bcl-xL and Bcl-2, leading to maintenance of the cells (22). Zhou et al. (23) demonstrated that mouse BM-MSCs, treated with E2 $\left(1 \times 10^{-7} \mathrm{M}\right)$, display a significant increase in ER- $\alpha$ mRNA and protein expression as well as proliferation rate. Together, these studies indicate that E2 is an important factor controlling the proliferation of BM-MSCs, which is mediated by various intercellular signaling pathways.

\section{The Role of E2 in Hematopoietic Regulation: Self-renewal and Differentiation}

With defining the role of $\mathrm{E} 2$ in regulating proliferation of various adult and pluripotent stem cells, attempts were also made to define the role of E2 in regulating HSC functions during self-renewal and differentiation (Table 1). First evidence regarding the mechanism of E2 action on hematopoietic stem and progenitor cells (HSPCs) in the BM has been reported by Illing et al. (24). The study demonstrated that E2 increases HSPC number with reconstitutive potential in the vascular niche, but not in the endosteal niche. This increase is associated with the enhanced entry of HSPCs into S-phase independent of its ER- $\alpha$-dependent anabolic bone effect. Similarly, the number and function of HSCs was significantly reduced in the ovariectomized (OVX) when compared with the Sham group (25). 
Table 1. The role E2 in the hematopoietic system

\begin{tabular}{|c|c|c|c|c|}
\hline Species & Function & ER dependency & Related signaling/molecules & References \\
\hline \multicolumn{5}{|l|}{$\mathrm{HSC}$} \\
\hline Mouse & $\begin{array}{l}\text { E2 increases number of functional HSCs in } \\
\text { the vascular niche }\end{array}$ & Independent & $\begin{array}{l}\text { May be mediated by another receptor, } \\
\text { such as GPR30 }\end{array}$ & 24 \\
\hline Rat & $\begin{array}{l}\text { The number of functional HSPCs in BM is } \\
\text { decreased in OVX group }\end{array}$ & Not defined & $\begin{array}{l}\text { via reduction in hematopoietic growth } \\
\text { factors (GM-CSF, SCF, and IL-3) }\end{array}$ & 25 \\
\hline Mouse & $\begin{array}{l}\text { While tamoxifen induces a pronounced reduction } \\
\text { in the number of MPP and ST-HSCs, LT-HSCs } \\
\text { are relatively preserved }\end{array}$ & ER- $\alpha$ dependent & $\begin{array}{l}\text { via differential apoptotic effects on } \\
\text { distinct HSPC subsets }\end{array}$ & 26 \\
\hline Mouse & E2 induces proliferation of LT-HSCs & ER- $\alpha$ dependent & Myc-targeted genes & 26 \\
\hline Mouse & E2 increases HSC division and erythropoiesis & ER- $\alpha$ dependent & $\begin{array}{l}\text { May be regulated by activating genes } \\
\text { with E2F1 motifs }\end{array}$ & 10 \\
\hline \multicolumn{5}{|c|}{ 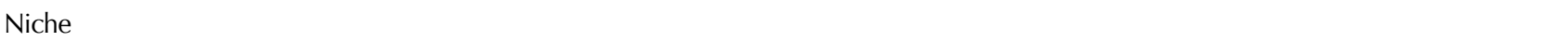 } \\
\hline Rat & $\begin{array}{l}\text { E2 induces the proliferation of HSCs by the } \\
\text { promotion of osteogenic differentiation of MSCs }\end{array}$ & Not defined & Mediated by GM-CSF and IL-6 & 38 \\
\hline Human & $\begin{array}{l}\text { Resveratrol (phytoestrogen) enhances osteoblastic } \\
\text { differentiation of BMMSCs }\end{array}$ & ER-dependent & via ERK1/2 activation & 20 \\
\hline Human & $\begin{array}{l}\text { E2 enhances oestoblastic differentiation of } \\
\text { BMMSCs }\end{array}$ & ER-dependent & via upregulation of Notch signaling & 18 \\
\hline Mouse & E2 promotes BMMSC osteogenesis & ER-dependent & $\begin{array}{l}\text { Activation of } \mathrm{Wnt} / \beta \text {-catenin signaling } \\
\text { via GPR40 upregulation }\end{array}$ & 40 \\
\hline Mouse & Maintenance of bone mass & ER- $\alpha$ dependent & Upregulation of Ctsk, TRAP, and FasL & 43,44 \\
\hline
\end{tabular}

Furthermore, the significant reduction of hematopoietic growth factors including GM-CSF, SCF, and IL-3 was observed in the OVX group compared with the corresponding Sham group. These findings suggest a definite role of E2 in the proliferation of HSCs in the BM. HSCs are characterized by hierarchical organization in their self-renewal and differentiation, thus attempts were made to determine the effects of E2 on specific HSPC subpopulations in the BM. Indeed, recent study showed that ER- $\alpha$ and ER- $\beta$ were differentially expressed in long-term (LT) repopulating HSC, multipotent hematopoietic progenitors (MPPs) and committed progenitors, suggesting differential role of E2 signaling in specific HSPC subpopulations (26). This study further demonstrated that while ER activation causes a rapid reduction in BM cellularity as well as the number of short-term (ST) HSCs and MPPs, the proliferation of quiescent LT-HSCs is induced by altered expression of c-Myc, associated with a loss of self-renewal activity and differentiation of HSCs. Notably, Nakada et al. (10) demonstrated that E2 promotes cell cycle activity of HSCs and MPPs in the BM, which is the tissue that does not show sex-specific morphological differences. In addition, HSCs in the female mice divide more frequently than in the male mice, which contributes to elevate the frequency of megakaryocyte-erythrocyte progenitor. This work paves the way towards a previously unexplored endocrine mechanism that controls HSC behavior and raises the question as to what effect does E2 have on LT repopulation of HSCs upon transplantation.

Human pluripotent stem cells (hPSCs) including ESCs, induced pluripotent stem cells (iPSCs), and ESCs derived somatic cell nuclear transfer are now being explored as a promising source for generating transplantable HSPCs and mature blood cells for treatment of various hematopoietic disorders (27). Although the role that E2 plays in hematopoietic development from hPSCs has not yet been defined, the expression of ER- $\alpha$ and ER- $\beta$ has been reported in the early stage of human embryoid bodies (28). This finding suggests the influence of E2 on the proliferation and hematopoietic differentiation of human PSCs. Indeed, treatment of E2 $\left(1 \times 10^{-5} \mathrm{M}\right)$ during spontaneous EB differentiation augments the expression level of brachyury mRNAs, associated with early hematopoietic specification. This contrasts with another study showing no alteration or reduction of brachyury expression in EBs treated with E2 $\left(1 \times 10^{-7} \mathrm{M}\right.$ and $\left.1 \times 10^{-9} \mathrm{M}\right)(29)$. This discrepancy between these two studies may have been due to different doses and the period (14 days vs 30 days) of E2 treatment. Another set of experimentation has been performed to examine the influences of endocrine disruptors (EDs) including xenoestrogen on the proliferation and differentiation of PSCs (29-32). These works suggest the possibility that these EDs are able to mimic estrogen and may have potential risks in hematopoietic development, although 
further studies are needed to support this possibility.

\section{HSC niche regulation by Estrogen}

Ontogeny of HSCs sequentially proceeds in discrete regions during embryogenesis where various cell components exert influence on the emergence, expansion, self-renewal and differentiation of HSCs (7). Despite the debate on the location of definitive hematopoiesis, HSCs are shown to first emerge from hemogenic endothelium in the aorta-gonad-mesonephros area in various model organisms and then migrate to the fetal liver for expansion (33). After birth, HSCs migrate to the BM from the fetal liver and predominantly reside in the BM in the adult. The function of HSCs is intimately regulated by the BM niche primarily consisting of nestin-expressing cells, CXCL12abundant reticular cells and osteoblasts (34). Mounting studies have shown that cell components in the BM niche regulate the quiescence, self-renewal, mobilization and differentiation of HSCs either through secreting or presenting a variety of signaling molecules on the cell surface (34). On the other hand, humoral factors and hormones in the circulation, in addition to its direct regulation of HSCs, can also influence the activities of the BM niche cells to indirectly modulate the function of HSCs (Table 1).

Osteoblasts, derived from MSCs, are one of the most important cell components in the BM niche. Previous studies have shown that osteoblasts can produce signaling molecules such as IL-6, GM-CSF, and Notch ligand Jagged 1 to regulate the activities of HSCs $(35,36)$. Elegant studies from Scadden's and Li's groups have demonstrated that parathyroid hormone (PTH) and BMP signaling can directly regulate osteoblasts to control the number and function of HSCs, respectively $(36,37)$. These studies suggest that hormone in the circulation may indirectly modulate HSCs through controlling osteoblasts in the BM niche. In line with this, Qiu et al. (38) has shown that E2 induces the proliferation of HSCs, which is dependent on that E2 promotes the osteogenic differentiation of MSCs. The effect of E2 on osteogenic differentiation of MSCs is mediated through ER expressed in MSCs $(20,39)$. Recent studies have shed light on understanding the downstream mechanisms underlying the process. Gao et al. (40) has reported that E2 may promote osteogenic differentiation of MSCs through regulating $G$ protein-coupled receptor 40 (GPR40). E2 has also been shown to augment osteogenic differentiation of MSCs by modulating both Wnt/ $\beta$-catenin and Notch signaling pathways $(40,18)$. Interestingly, previous study has shown that bone cells express estrogen receptor, suggesting that E2 may play a role in the bone remodeling (41). Knockout of ER- $\beta$ study demonstrated that ER- $\beta$ represses bone growth during female adolescence (42). Moreover, E2 has been shown to maintain bone mass by inducing apoptosis of osteoclast $(43,44)$. Taken together, it suggests that E2 may be involved in the remodeling of the BM niche through controlling the activities of osteoclasts and bone cells. Thus, E2 may control the BM niche to regulate the biological functions of HSCs through diverse mechanisms where multiple signaling pathways are likely to be engaged.

\section{Conclusion}

A great deal of studies demonstrated that E2 clearly influences the proliferation and differentiation of various stem cell types including HSCs via different signaling pathways. A better understanding of the effects of E2 and other steroid hormones on HSCs will allow stem cell researchers to improve the functions of HSCs originated from BM and hPSCs, with the ultimate goal of generating LT-HSCs and mature blood cells for the treatment of hematopoietic disorders.

\section{Acknowledgments}

This work was supported by the Basic Science Research Program through the National Research Foundation of Korea (NRF) funded by the Ministry of Education, Science and Technology (2013K1A3A1A20046548) and by a grant of the Korea Health Technology R\&D Project, Ministry of Health and Welfare, Republic of Korea (A120262). This work was supported by grants to J.J from the International S\&T Cooperation Program of the Ministry of Science and Technology of China (2014DFG32790).

\section{Potential conflict of interest}

The authors have no conflicting financial interest.

\section{References}

1. Daley GQ. Stem cells: roadmap to the clinic. J Clin Invest 2010;120:8-10

2. Fox IJ, Daley GQ, Goldman SA, Huard J, Kamp TJ, Trucco M. Stem cell therapy. Use of differentiated pluripotent stem cells as replacement therapy for treating disease. Science 2014;345:1247391

3. Zon LI. Intrinsic and extrinsic control of haematopoietic stem-cell self-renewal. Nature 2008;453:306-313

4. Pera MF, Tam PP. Extrinsic regulation of pluripotent stem cells. Nature 2010;465:713-720

5. Cook D, Genever P. Regulation of mesenchymal stem cell differentiation. Adv Exp Med Biol 2013;786:213-229

6. Hong SH, Kim KS, Oh IH. Concise review: Exploring 
miRNAs--toward a better understanding of hematopoiesis. Stem Cells 2015;33:1-7

7. Orkin SH, Zon LI. Hematopoiesis: an evolving paradigm for stem cell biology. Cell 2008;132:631-644

8. Ray R, Novotny NM, Crisostomo PR, Lahm T, Abarbanell A, Meldrum DR. Sex steroids and stem cell function. Mol Med 2008;14:493-501

9. Calvanese V, Lee LK, Mikkola HK. Sex hormone drives blood stem cell reproduction. EMBO J 2014;33:534-535

10. Nakada D, Oguro H, Levi BP, Ryan N, Kitano A, Saitoh Y, Takeichi M, Wendt GR, Morrison SJ. Oestrogen increases haematopoietic stem-cell self-renewal in females and during pregnancy. Nature 2014;505:555-558

11. Kodaman PH, Taylor HS. Hormonal regulation of implantation. Obstet Gynecol Clin North Am 2004;31:745766

12. Barnabas O, Wang H, Gao XM. Role of estrogen in angiogenesis in cardiovascular diseases. J Geriatr Cardiol 2013;10:377-382

13. Khosla S, Oursler MJ, Monroe DG. Estrogen and the skeleton. Trends Endocrinol Metab 2012;23:576-581

14. Pellegrini M, Pallottini V, Marin R, Marino M. Role of the sex hormone estrogen in the prevention of lipid disorder. Curr Med Chem 2014;21:2734-2742

15. Vrtačnik P, Ostanek B, Mencej-Bedrač S, Marc J. The many faces of estrogen signaling. Biochem Med (Zagreb) 2014;24: 329-342

16. Levin ER. Integration of the extranuclear and nuclear actions of estrogen. Mol Endocrinol 2005;19:1951-1959

17. Hong L, Zhang G, Sultana H, Yu Y, Wei Z. The effects of $17-\beta$ estradiol on enhancing proliferation of human bone marrow mesenchymal stromal cells in vitro. Stem Cells Dev 2011;20:925-931

18. Fan JZ, Yang L, Meng GL, Lin YS, Wei BY, Fan J, Hu HM, Liu YW, Chen S, Zhang JK, He QZ, Luo ZJ, Liu J. Estrogen improves the proliferation and differentiation of hBMSCs derived from postmenopausal osteoporosis through notch signaling pathway. Mol Cell Biochem 2014;392:85-93

19. Chen FP, Hu CH, Wang KC. Estrogen modulates osteogenic activity and estrogen receptor mRNA in mesenchymal stem cells of women. Climacteric 2013;16:154-160

20. Dai Z, Li Y, Quarles LD, Song T, Pan W, Zhou H, Xiao $Z$. Resveratrol enhances proliferation and osteoblastic differentiation in human mesenchymal stem cells via ER-dependent ERK1/2 activation. Phytomedicine 2007;14:806-814

21. Yun SP, Lee MY, Ryu JM, Song CH, Han HJ. Role of HIF-1alpha and VEGF in human mesenchymal stem cell proliferation by 17beta-estradiol: involvement of PKC, PI3K/Akt, and MAPKs. Am J Physiol Cell Physiol 2009; 296:C317-326

22. Ayaloglu-Butun F, Terzioglu-Kara E, Tokcaer-Keskin Z, Akcali KC. The effect of estrogen on bone marrow-derived rat mesenchymal stem cell maintenance: inhibiting apoptosis through the expression of Bcl-xL and Bcl-2. Stem Cell Rev 2012;8:393-401

23. Zhou S, Zilberman Y, Wassermann K, Bain SD, Sadovsky
Y, Gazit D. Estrogen modulates estrogen receptor alpha and beta expression, osteogenic activity, and apoptosis in mesenchymal stem cells (MSCs) of osteoporotic mice. J Cell Biochem Suppl 2001;Suppl 36:144-155

24. Illing A, Liu P, Ostermay S, Schilling A, de Haan G, Krust A, Amling M, Chambon P, Schinke T, Tuckermann JP. Estradiol increases hematopoietic stem and progenitor cells independent of its actions on bone. Haematologica 2012; 97:1131-1135

25. Qiu X, Yuan XG, Jin XL, He X, Zhu L, Zhao XY. Oestrogen-deficiency inducing haematopoiesis dysfunction via reduction in haematopoietic stem cells and haematopoietic growth factors in rats. Int J Exp Pathol 2012;93: 179-187

26. Sánchez-Aguilera A, Arranz L, Martín-Pérez D, GarcíaGarcía A, Stavropoulou V, Kubovcakova L, Isern J, MartínSalamanca S, Langa X, Skoda RC, Schwaller J, MéndezFerrer S. Estrogen signaling selectively induces apoptosis of hematopoietic progenitors and myeloid neoplasms without harming steady-state hematopoiesis. Cell Stem Cell 2014;15:791-804

27. Kardel MD, Eaves CJ. Modeling human hematopoietic cell development from pluripotent stem cells. Exp Hematol 2012;40:601-611

28. Hong SH, Nah HY, Lee YJ, Lee JW, Park JH, Kim SJ, Lee JB, Yoon HS, Kim CH. Expression of estrogen receptor-alpha and -beta, glucocorticoid receptor, and progesterone receptor genes in human embryonic stem cells and embryoid bodies. Mol Cells 2004;18:320-325

29. Kim H, Kim YY, Ku SY, Kim SH, Choi YM, Moon SY. The effect of estrogen compounds on human embryoid bodies. Reprod Sci 2013;20:661-669

30. Yang L, Luo L, Ji W, Gong C, Wu D, Huang H, Liu Q, Xia B, Hu G, Zhang W, Zhang Q, Liu J, Zhang W, Zhuang Z. Effect of low dose bisphenol A on the early differentiation of human embryonic stem cells into mammary epithelial cells. Toxicol Lett 2013;218:187-193

31. Jung EM, Choi KC, Yu FH, Jeung EB. Effects of 17beta-estradiol and xenoestrogens on mouse embryonic stem cells. Toxicol In Vitro 2010;24:1538-1545

32. Annab LA, Bortner CD, Sifre MI, Collins JM, Shah RR, Dixon D, Karimi Kinyamu H, Archer TK. Differential responses to retinoic acid and endocrine disruptor compounds of subpopulations within human embryonic stem cell lines. Differentiation 2012;84:330-343

33. Dzierzak E, Speck NA. Of lineage and legacy: the development of mammalian hematopoietic stem cells. Nat Immunol 2008;9:129-136

34. Mercier FE, Ragu C, Scadden DT. The bone marrow at the crossroads of blood and immunity. Nat Rev Immunol 2011;12:49-60

35. Taichman RS. Blood and bone: two tissues whose fates are intertwined to create the hematopoietic stem-cell niche. Blood 2005;105:2631-2639

36. Calvi LM, Adams GB, Weibrecht KW, Weber JM, Olson DP, Knight MC, Martin RP, Schipani E, Divieti P, 
Bringhurst FR, Milner LA, Kronenberg HM, Scadden DT. Osteoblastic cells regulate the haematopoietic stem cell niche. Nature 2003;425:841-846

37. Zhang J, Niu C, Ye L, Huang H, He X, Tong WG, Ross J, Haug J, Johnson T, Feng JQ, Harris S, Wiedemann LM, Mishina Y, Li L. Identification of the haematopoietic stem cell niche and control of the niche size. Nature 2003;425: 836-841

38. Qiu X, Jin X, Shao Z, Zhao X. $17 \beta$-estradiol induces the proliferation of hematopoietic stem cells by promoting the osteogenic differentiation of mesenchymal stem cells. Tohoku J Exp Med 2014;233:141-148

39. Yao XL, Li L, He XL, Cui L, Kuang W, Tang M. Activation of $\beta$-catenin stimulated by mechanical strain and estrogen requires estrogen receptor in mesenchymal stem cells (MSCs). Eur Rev Med Pharmacol Sci 2014;18:31493155

40. Gao B, Huang Q, Jie Q, Wang L, Zhang HY, Liu J, Yang L, Luo ZJ. Dose-response estrogen promotes osteogenic differentiation via GPR40 (FFAR1) in murine BMMSCs.
Biochimie 2015;110:36-44

41. Eriksen EF, Colvard DS, Berg NJ, Graham ML, Mann KG, Spelsberg TC, Riggs BL. Evidence of estrogen receptors in normal human osteoblast-like cells. Science 1988;241:84-86

42. Windahl SH, Vidal O, Andersson G, Gustafsson JA, Ohlsson C. Increased cortical bone mineral content but unchanged trabecular bone mineral density in female ERbeta(-/-) mice. J Clin Invest 1999;104:895-901

43. Imai Y, Youn MY, Kondoh S, Nakamura T, Kouzmenko A, Matsumoto T, Takada I, Takaoka K, Kato S. Estrogens maintain bone mass by regulating expression of genes controlling function and life span in mature osteoclasts. Ann N Y Acad Sci 2009;1173 Suppl 1:E31-E39

44. Nakamura T, Imai Y, Matsumoto T, Sato S, Takeuchi K, Igarashi K, Harada Y, Azuma Y, Krust A, Yamamoto Y, Nishina H, Takeda S, Takayanagi H, Metzger D, Kanno J, Takaoka K, Martin TJ, Chambon P, Kato S. Estrogen prevents bone loss via estrogen receptor alpha and induction of Fas ligand in osteoclasts. Cell 2007;130:811-823 